\title{
PENERAPAN PSIKOEDUKASI TENTANG PENGETAHUAN KESIAPAN SEKOLAH ANAK TERHADAP IBU UNTUK MENINGKATKAN KEMANDIRIAN ANAK
}

\author{
Nur Asiyah ${ }^{1 *}$, Anita Mauliyah ${ }^{2}$ \\ ${ }^{1}$ Universitas 17 Agustus 1945 Surabaya, Surabaya, Jawa Timur, Indonesia \\ ${ }^{2}$ STAI YPBWI Surabaya, Surabaya, Jawa Timur, Indonesia \\ *nurasiyah.se@gmail.com
}

Received: April 22 ${ }^{\text {nd }}, 2021$

Revised: July $31^{\text {st }}, 2021$

Accepted: August $02^{\text {nd }}, 2021$

\begin{abstract}
The importance of mother's skills towards children is needed so that children become independent. In this case, efforts are needed to improve maternal parenting skills. One of the efforts that can be done is the provision of psychoeducation about knowledge of school readiness for mothers. Therefore, this study aims to determine whether there is an effect of child independence after the mother is given knowledge about psychoeducation. The mothers who were given the knowledge about Psychoeducation were 30 people who were the guardians of Hasanuddin Kindergarten students. The research data was collected with a focus on the children's independence scale and school readiness scale, because the research data was not normally distributed, the data analysis used in this study was Non Parametic Wilcoxson. From the results of the analysis, the value of $t$ count is 0.015 and the value of sig. of 0.988 which means that there is no difference in the independence of the child before the mother is given psychoeducation and after being given psychoeducation.
\end{abstract}

Keywords: child Independence; children; psychoeducation

\section{PENDAHULUAN}

Proses tumbuh kembang anak usia dini (PAUD) terkait dengan bagaimana sikap belajarnya, oleh karena itu sejak awal orang tua harus mempersiapkan diri dengan berbagai keterampilan yang berkaitan dengan perkembangan anak, seperti melakukan pola asuh yang baik dan memberikan lingkungan yang baik bagi anak. Anak yang mendapat bimbingan sejak dini akan mampu meningkatkan kesehatan dan kesejahteraan fisik dan mentalnya yang berdampak pada peningkatan prestasi belajar, etos kerja dan produktivitas anak. Pada akhirnya anak akan mampu mandiri dan mengoptimalkan potensinya. Secara alami, anak sudah memiliki keinginan untuk mandiri. Terkadang lebih bahagia bisa menjaga diri sendiri daripada dilayani (Roza, 2019). 
Anak adalah manusia tahap awal yang memiliki potensi dan harus dibantu perkembangnnya. Anak memiliki ciri-ciri tertentu yang unik dan tidak sama dengan orang dewasa, dimana anak selalu dinamis, aktif, selalu ingin tahu dan antusias terhadap apa yang, didengar, dilihat, dan dirasakannya seakan tidak pernah berhenti belajar dan bereksplorasi. Anak memiliki karakteristik yang khas dan unik, serta memiliki tahap tumbuh kembang yang berbeda dengan periode tumbuh kembang anak lainnya (Ariyanti, 2016).

Taman kanak-kanak adalah permulaan dari perkenalan anak terhadap lingkungan sekitar yang ada pada masyarakat umum, diluar lingkungan keluarganya. Taman kanak-kanak adalah lembaga yang selain memberikan kesempatan bermain sambil belajar kepada anak, juga memberikan pendidikan kepada anak supaya tumbuh mandiri, bersosialisasi dan mendapatkan berbagai keterampilan lainnya. (Nurhayati, 2018)

Anak pada usia Taman kanak-kanak sedang mengalami masa perkembangan yang sangat pesat. Pada masa ini proses perubahan fisik, sosial dan emosional pada anak berlangsung dengan cepat yang dipengaruhi oleh berbagai faktor, baik faktor dari diri sendiri maupun lingkungannya. Pertumbuhan dan perkembangan anak usia taman kanak-kanak ini dapat dipantau melalui ukuran fisiknya dan melalui pengamatan terhadap sikap dan perilaku anak. (Elihami \& Ekawati, 2020).

Standar Nasional PAUD (Pendidikan Anak Usia Dini) disusun dengan tujuan agar setiap anak dapat mencapai tingkat perkembangan yang maksimal, yang meliputi perkembangan, bahasa, motorik kasar dan halus, kognitif, moral, pemahaman agama dan sosial emosional. (Zamzami, 2020)

Kesiapan anak untuk bersekolah sangat dibutuhkan bagi anak-anak yang akan masuk sekolah. karena kesiapan anak untuk bersekolah dapat mendukung keberhasilan prestasi akademik (Yulisetyaningrum, 2019). Anak-anak yang belum siap bersekolah lebih mudah mengalami frustasi di sekolah yang berakibat pada perilaku anak menarik diri lingkungan sekolah, menunjukkan gejala mogok sekolah, prestasi yang rendah, dan perilaku acuh tak acuh. (Mashfufah, 2020).

Kemandirian merupakan perilaku dan sikap yang tidak bergantung pada orang lain untuk menyelesaikan masalahya sendiri. Kemandirian harus dirangsang 
sejak usia dini, karena anak usia dini merupakan masa keemasan dimana segala aspek perkembangan memegang peranan penting dalam tumbuh kembang anak selanjutnya, termasuk sikap kemandirian. Salah satu cara untuk melatih kemandirian anak adalah dengan menstimulasi kemandirian anak melalui kegiatan yang diberikan oleh guru. Oleh karena itu, sangat penting untuk membuat kegitan yang menstimulasi kemandirian anak di sekolah (Nova, 2019).

Peran ibu sangat penting dalam perkembangan anak khususnya pada usia taman kanak-kanak. Peran ibu sangat dibutuhkan untuk memberikan stimulasi pada aktivitas anak. Pengembangan kecerdasan dan mempersiapkan anak memasuki dunia sekolah (Hati \& Lestari, 2016; Novianti \& Garzia, 2020).

Semua orang tua mengharapkan anaknya tumbuh menjadi orang yang pintar, bahagia, dan mempunyai berkepribadian baik. Orang tua diwajibkan dapat mengamati dan memberikan evaluasi terkait perkembangan anak untuk mewujudkan harapan tersebut (Supriatna, 2018).

Berdasarkan observasi pada tanggal 14 Agustus 2017 di Taman KanakKanak Hasanuddin, ditemukan beberapa anak yang masih didampingi ibunya saat mengikuti proses belajar mengajar di sekolah, tidak sedikit anak-anak masih menangis mencari ibunya saat dikerjai oleh temannya ataupun saaat anak tidak dapat menyelesaikan tugas yang diberikan oleh gurunya, bahkan ibu-ibu sampai menunggu disekolah hingga anak-anaknya pulang disekolah. Bentuk ketidak mandirian anak seperti ini ditemui hampir setiap hari di sekolah.

Keterampilan pengasuhan ibu sangat dibutuhkan oleh seorang ibu agar anaknya menjadi mandiri, karena pada kenyataannya pendidikan utama bersumber dari keluarga terutama pendidikan oleh ibu. Dibandingkan dengan sekolah, orang tua lebih bertanggung jawab atas perkembangan anak. Pola asuh yang diterapkan oleh ibu sangat menentukan perilaku anak karena orang tua merupakan panutan utama bagi anak. (Nooraeni, 2017).

Berdasarkan pemaparan tentang fakta bahwa masih banyak anak yang perlu ditingkatkan lagi kemandiriannya dan ibu-ibu agar lebih siap mendampingi proses tumbuh kemandirian anak, maka diperlukan suatu upaya atau dalam penelitian ini berupa psikoedukasi agar ibu lebih siap dan mampu membimbing anaknya agar lebih mandiri. (Haryani, Muntamah \& Astuti, 2020). 
Psikoedukasi 'tentang pengetahuan kesiapan sekolah anak terhadap lbu untuk meningkatkan kemandirian anak' mengacu pada triple-p (positive parenting program) yang dikembangkan oleh Sandes pada tahun 1999 sebagai program intervensi untuk meningkatkan perilaku mandiri pada anak. Kegiatan program psikoedukasi untuk meningkatkan kemampuan didaktik yaitu memberikan informasi tentang suatu materi yang dalam penelitian ini lebih difokuskan pada peningkatan pengetahuan kesiapan ibu untuk menyekolahkan anaknya sebagai upaya meningkatkan kemandirian anak (Syuhada, Indria \& Firmansyah, 2020).

Peneliti berpendapat bahwa pemberian psikoedukasi tentang pengetahuan kesiapan sekolah seorang anak perlu diberikan kepada wali siswa TK Hasanuddin dalam hal ini adalah ibu-ibu yang masih menunggu anaknya di sekolah (Purbasafir, 2018).

Dalam menerapkan psikoedukasi diperlukan beberapa tahapan, tahap pertama adalah memberikan pelatihan. Metode ceramah adalah salah satu metode pelatihan yang bisa digunakan untuk menyampaikan materi kepada ibuibu. Alat bantu audio visual juga diperlukan untuk menampilkan materi. Berbagi pendapa sebagai sharing secsion, dilanjutkan dengan demonstrasi dan permainan. Materi yang diberikan selama psikoedukasi berkaitan dengan tahapan tumbuh kembang anak dan cara mendidik anak agar mandiri (Putriyanti \& Tina, 2020).

Peneliti berharap setelah diberikan psikoedukasi terdapat perubahan positif pada ibu sehingga ibu lebih siap melepas anaknya ke sekolah, apabila anak sudah siap bersekolah maka dapat meningkatkan kemandirian anak. (Insiyah \& Sulistyowati, 2019).

\section{METODE PENELITIAN}

Penelitian ini merupakan penelitian eksperimen yang dilakukan pada 16 Desember 2017 di TK Hasanuddin Surabaya. Lokasi ini dipilih karena terdapat anak-anak yang masih kurang mandiri, ini terlihat dari banyaknya anak yang masih dijaga ibunya saat di sekolah (Arifin, 2020).

Populasi ibu-ibu wali sebanyak 80 orang, sampel yang diambil sebanyak 30 orang. Metode pengumpulan data yang digunakan dalam penelitian ini adalah 
pretest dan posttest. Alasan peneliti menggunakan pretest dan posttest untuk mengukur subjek apakah ada perubahan sebelum diberikan psikoedukasi dan setelah diberikan psikoedukasi (Ismawati \& Prasetyo, 2020; Winanda, Putra, \& Zufriady, 2020).

Instrumen yang digunakan dalam penelitin ini adalah skala kemandirian dan skala kesiapan sekolah. Selanjutnya data yang didapat dari penelitian diolah dan dianalisis dengan menggunakan bantuan SPSS (Ihwan \& Rofiqi, 2020).

Karena data penelitian tidak berdistribusi normal, maka analisis statistik yang semula akan dianalisis menggunakan uji pairid t test, selanjutnya akan diganti dengan analisis Non Parametic Wilcoxson (Rudianto, 2020).

\section{HASIL DAN PEMBAHASAN}

\section{Hasil Penelitian}

Melihat hasil dari olah data uji normalitas dan homogenitas, maka analisis statistik yang bisa digunakan adalah Uji Wilcoxon Signed Rank Test. Dan dari hasil analisis yang dilakukan menunjukkan tidak ada perbedaan yang signifikan antara pretest dan posttest sebagai pembahasab beikut:

a. Uji Wilcoxon Signed Rank Test Kemandirian Anak yaitu ditunjukkan dengan nilai Z sebesar -0,484 dan nilai sig. sebesar 0,629 ( $p>0,05)$, Artinya secara keseluruhan tidak ada perbedaan antara sampel setelah diberikan perlakuan berupa pelatihan psikoedukasi dengan sebelum diberikan perlakuan. Hal ini menunjukkan bahwa pelatihan psikoedukasi untuk kesiapan sekolah anak bagi ibu kurang efektif untuk meningkatkan kemandirian anak TK Hasanuddin. Hipotesis yang menyatakan ada perbedaan kemandirian anak pada kelompok eksperimen pretest dan posttest ditolak.

b. Uji Wilcoxon Signed Rank Test Pengetahuan Kesiapan Sekolah yaitu ditunjukkan dengan hasil nilai $Z$ sebesar -0,826 dan nilai sig. sebesar 0,409 ( $p>0,05)$, Artinya secara keseluruhan kelompok tidak ada perbedaan antara sampel diberikan perlakuan berupa pelatihan psikoedukasi dengan sebelum diberikan perlakuan. Ini menunjukkan pelatihan itu Psikoedukasi 
kesiapan sekolah anak terhadap Ibu tidak memberikan pengaruh di dalam meningkatkan kemandirian anak TK Hasanuddin. Hipotesis yang menyatakan bahwa ada perbedaan kemandirian anak pada kelompok eksperimen pretest dengan post test ditolak.

\section{Pembahasan Peneltian}

Berdasarkan hasil analisis data yang telah dilakukan, didapatkan bahwa tidak terdapat perbedaan yang signifikan antara sebelum diberikan pelatihan Psikoedukasi dengan setelah diberikan pelatihan Psikoedukasi. Hal ini dikarenakan pada saat diberikan pelatihan Psikoedukasi, responden tidak dalam tingkat konsentrasi yang baik, karena pada saat itu bersamaan dengan pengambilan rapor anaknya, sehingga responden tidak dapat berpartisipasi secara penuh untuk mengikuti materi pelatihan.

Melihat hasil hipotesis ditolak maka dilakukanlah obsevasi dan wawancara kepada wali kelas dan wali murid yang mengikuti pelatihan. Hasil wawancara dengan wali kelas didapatkan hasil bahwa setelah di berikan pelatihan ternyata masih banyak wali murid yang masih menunggu anakanya di sekolah dan masih ada anak yang menanggis ketika ditinggal oleh ibunya, hal ini yang memperkuat bahwa tidak ada pengaruh yang signifikan setelah di lakukan psikoedukasi

Selain pemaparan di atas, juga berdasarkan perhitungan selisih Hypothetic Men dan Empirical Men dapat disimpulkan bahwa nilai Hypothetic Men untuk independensi adalah 84 dan Empirical Men adalah 109 (84 <109), yang berarti Hipotesis $M$ lebih kecil daripada M Empiris, hal ini menggambarkan bahwa Sampel sudah memiliki pengetahuan dalam membuat anak mandiri. Nilai Hypothetic Men untuk kesiapan sekolah 96 dan nilai Empirical Men $137(96<137)$ yang berarti nilai Hypothetic $M$ lebih kecil dari nilai Empirical $M$, hal ini menggambarkan bahwa sampel juga memiliki kesiapan untuk menyekolahkan anaknya. Karena alasan diatas maka sampel merasa tidak terlalu penting saat diberikan Pelatihan Psikoedukasi, padahal ada beberapa sampel yang antusias mengikuti pelatihan. 


\section{SIMPULAN}

Berdasarkan pembahasan hasil penelitian, maka dapat disimpulkan bahwa tidak ada perbedaan yang signifikan antara sebelum diberikan pelatihan Psikoedukasi dan setelah diberikan pelatihan Psikoedukasi. Sehingga hipotesis penelitian ini yang menyatakan bahwa pelatihan Psikoedukasi tentang kesiapan sekolah anak bagi ibu, berpengaruh terhadap kemandirian anak di TK Hasanuddin Surabaya ditolak.

Alasan mengapa hipotesis ini tertolak, adalah karena ibu-ibu tidak fokus terhadap pelatihan yang diberikan, hal ini terjadi karena ibu-ibu keluar masuk ruangan saat pelatihan berlangsung, terlebih lagi terdapat ibu-ibu yang membawa balita sehingga tidak memperdulikan materi pelatihan yang diberikan.

\section{DAFTAR PUSTAKA}

Arifin, Z. (2020). Metodologi penelitian pendidikan. Jurnal Al-Hikmah, 1(1).

Ariyanti, T. (2016). Pentingnya Pendidikan Anak Usia Dini Bagi Tumbuh Kembang Anak The Importance Of Childhood Education For Child Development. Dinamika Jurnal IImiah Pendidikan Dasar, 8(1).

Elihami, E., \& Ekawati, E. (2020). Persepsi revolusi mental orang tua terhadap pendidikan anak usia dini. Jurnal edukasi nonformal, 1(2), 16-31.

Haryani, S., Muntamah, U., \& Astuti, A. P. (2020). Efektifitas Terapi Psikoedukasi terhadap Peningkatan Tumbuh Kembang Anak. Jkg (Jurnal Keperawatan Global), 5(1), 31-36.

Hati, F. S., \& Lestari, P. (2016). Pengaruh pemberian stimulasi pada perkembangan anak usia 12-36 bulan di Kecamatan Sedayu, Bantul. Jurnal Ners dan kebidanan indonesia, 4(1), 44-48.

Ihwan, M., \& Rofiqi, M. (2020). Sistem Penjaminan Mutu Internal Pendidikan Dasar (Studi Kasus Di SDN 1 Brotonegaran) (Doctoral dissertation, IAIN Ponorogo).

Insiyah, I., \& Sulistyowati, E. C. (2019). Parenting Psikoedukasi Dalam Mendukung Perkembangan Sosial Dan Emosional Anak Usia Pra Sekolah Di Kota Surakarta. JKG (JURNAL KEPERAWATAN GLOBAL), 4(2), 74-80. 
Ismawati, D., \& Prasetyo, I. (2020). Efektivitas pembelajaran menggunakan video zoom cloud meeting pada anak usia dini era pandemi covid-19. Jurnal Obsesi: Jurnal Pendidikan Anak Usia Dini, 5(1), 665-675.

Mashfufah, S. R., Rudiyanto, R., \& Listiana, A. (2020). persepsi guru taman kanak-kanak (tk) terhadap kemampuan perkembangan kognitif bahasa sebagai aspek penting dalam kesiapan bersekolah anak (school readiness). Edusentris, 6(3), 130-138.

Nooraeni, R. (2017). Implementasi Program Parenting Dalam Menumbuhkan Perilaku Pengasuhan Positif Orang Tua Di PAUD Tulip Tarogong Kaler Garut. Jurnal Pendidikan Luar Sekolah, 13(2).

Nova, D. D. R., \& Widiastuti, N. (2019). Pembentukan Karakter Mandiri Anak Melalui Kegiatan Naik Transportasi Umum. Comm-Edu (Community Education Journal), 2(2), 113-118.

Novianti, R., \& Garzia, M. (2020). Parental Engagement in Children's Online Learning During COVID-19 Pandemic. Journal of Teaching and Learning in Elementary Education, 3(2), 117 - 131.

Nurhayati, E. (2018). Psikologi pendidikan inovatif (Vol. 2). Pustaka Pelajar.

Purbasafir, T. F. (2018). Psikoedukasi untuk meningkatkan parenting self-efficacy pada ibu anak penyandang autisme (Doctoral dissertation, University of Muhammadiyah Malang).

Putriyanti, C. E., \& Tina, S. A. (2020). Pemberian Media Audiovisual Terhadap perkembangan Anak. Syntax Literate; Jurnal IImiah Indonesia, 5(10), 10361052.

Roza, D., Nurhafizah, N., \& Yaswinda, Y. (2019). Urgensi profesionalisme guru pendidikan anak usia dini dalam penyelenggaraan perlindungan anak. Jurnal Obsesi: Jurnal Pendidikan Anak Usia Dini, 4(1), 277.Azwar,S. (2015). Reliabilitas dan Validitas. Yogyakarta: Pustaka Pelajar.

Rudianto, D., Putri, N. N., Said, M., Anjani, J. M., Erliyani, F., \& Muliawati, T. (2020). Pengaruh Hubungan E-learning Dalam Mata Kuliah MAFIKI di Institut Teknologi Sumatera Menggunakan Metode Wilcoxon. Indonesian Journal of Applied Mathematics, 1(1), 
Supriatna, D. (2018). Motivasi Orang Tua Memilih Pondok Pesantren Untuk Anaknya. Intizar, 24(1), 1-18.

Syuhada, A. R., Indria, D. M., \& Firmansyah, M. (2020). Pengaruh Psikoedukasi terhadap Pengetahuan, Motivasi dan Perubahan Sikap-Prilaku Penyalahgunaan Narkoba terhadap Anak Usia 10-12 Tahun. Jurnal Bio Komplementer Medicine, 7(1).

Winanda, W., Putra, Z. H., Zufriady, Z. (2020). Pengaruh model pembelajaran kooperatif dengan bantuan media tulang napier terhadap hasil belajar matematika siswa kelas III SD IT Diniyah Pekanbaru. Tunjuk Ajar: Jurnal Penelitian IImu Pendidikan, 3(2), $250 \quad-\quad 260$. http://dx.doi.org/10.31258/jta.v3i2.250-260

Yulisetyaningrum, Y. (2019). Perkembangan Sosial Emosional Anak Usia Pra Sekolah. Jurnal Ilmu Keperawatan Dan Kebidanan, 10(1), 221-228.

Zamzami, E. M. (2020). Aplikasi Edutainment Pendukung Pembelajaran Jarak Jauh TK Merujuk Standar Nasional PAUD. Jurnal Obsesi: Jurnal Pendidikan Anak Usia Dini, 5(2), 985-995. 